\title{
Probability of pregnancy and risk factors of the Ovsynch program and its modification in dairy cows - a review
}

\author{
Jędrzej M. Jaśkowski ${ }^{1}$, Jarosław Sobolewski ${ }^{1}$, Magdalena Herudzińska ${ }^{1}$, Marcelina \\ Nalaskowska ${ }^{1}$, Bartłomiej M. Jaśkowski², Jakub Kulus ${ }^{1}$, Klaus-Peter Brüssow ${ }^{1}$ \\ ${ }^{1}$ Nicolaus University in Toruń, Centre for Veterinary Sciences, Toruń, Poland \\ ${ }^{2}$ Wroclaw University of Environmental and Life Sciences, Faculty of Veterinary Medicine, \\ Department of Reproduction and Clinic of Farm Animals, Wrocław, Poland
}

\author{
Received April 13, 2018 \\ Accepted August 13, 2018
}

\begin{abstract}
The Ovsynch programme is one of the most frequently used procedures in managing dairy cattle reproduction. There are many studies evaluating the effectiveness of the Ovsynch programme. However, few of them assess the impact of factors that can lead to a decrease in the pregnancy rate and thus, reduce the success of the Ovsynch programme. This review aims to examine the impact of both individual and environmental factors on the likelihood of pregnancy. The risk factors described include: the body condition, age, number and stage of lactation, production level, occurrence of diseases and postpartum complications, functional status of the ovaries, oestrous cycle phase, temperature, season and year, and program start-up after calving. Possible modifications of the Ovsynch programme are presented in order to increase its effectiveness and to determine the best time to start it. Additionally, attention was paid to pregnancy losses during the Ovsynch programme which ultimately decrease pregnancy rates. The impact of this many factors on the efficiency of the Ovsynch suggests the need to adjust the synchronization program each time to the individual situation of the herd.
\end{abstract}

Synchronization programmes, reproduction, cattle, fertility

The Ovsynch synchronization programme becomes a standard component in the current breeding management of cows (Klindworth et al. 2004; Macmillan 2010; Nowicki et al. 2017). The original procedure was proposed by Pursley et al. (1995) more than 20 years ago. Cows were injected with gonadotropin releasing hormone $(\mathrm{GnRH})$ at a random stage of their oestrous cycle, followed by an injection of prostaglandin seven days later and a final injection of GnRH two days later. Cows were fixed-time artificially inseminated $24 \mathrm{~h}$ after the last GnRH injection. According to survey research, timed artificial insemination (TAI) is used in 20\% of Canadian herds (Denis-Robichaud et al. 2016). Many programmes are based on protocols that allow TAI without a problematic detection of oestrus (Rabiee et al. 2005). Oestrus detection becomes problematic in modern herds where individual animal monitoring is difficult and often subjective. This problem may also occur in herds where cows are milked in robotic systems which minimize interactions between staff and cows. Additionally, high producing cows have less obvious symptoms of oestrus. This is partly because of housing systems combined with intensive feeding and milking, due to higher metabolic clearance rates of reproductive hormones like oestradiol, and partly because of the increasing prevalence of prolonged postpartum anoestrus and reproductive tract pathologies (Jaśkowski et al. 2006; Macmillan 2010; Wankhade et al. 2017; Jaśkowski et al. 2018a). Out of the most frequently used cow reproduction management programs, the Ovsynch is by far the most common one. In Canada it makes up for $58 \%$ of all TAI programs (Denis-Robichaud et al. 2016). In the USA, Ovsynch/TAI were used in $87 \%$ of the herds, with $86 \%$ synchronizing first services, $77 \%$ resynchronizing repeat services, and 59\% treating cystic, anoestrous or anovular cows (Caraviello et al. 2006). When choosing this reproductive technology, the increased workload and the costs of

Address for correspondence:

Magdalena Herudzińska

Centre for Veterinary Sciences

Nicolaus University in Torun

ul. Gagarina 7; 87-100 Toruń, Poland

Phone: 661646115

E-mail: magdalenaherudzinska6@gmail.com

http://actavet.vfu.cz/ 
hormone administration should be taken into account (Rabiee et al. 2005). Nevertheless, the economic calculation is in favour of this method. The cost-benefit-analysis revealed lower total costs and costs per pregnancy in cows using Ovsynch compared to the traditional care (Klindworth et al. 2004).

The effectiveness of the Ovsynch programme depends on many factors. This study aims to present those factors.

\section{Body condition}

The influence of body condition on the effectiveness of the Ovsynch/TAI programme was highlighted in many studies (Moreira et al. 2000; Jeong et al. 2014). The pregnancy rates after Ovsynch/TAI protocol were lower for cows with a body condition score (BCS) $<2.5$ than for cows with a higher one on day $27(18.1 \%$ vs $33.8 \%)$ and on day 45 after insemination (11.1\% vs $25.6 \%$ ), respectively (Moreira et al. 2000).

Cows with a BCS of 3.00 had a higher conception rate than those with a BCS of $>3.25$ and $<2.75$ (Klindworth et al. 2001). The conception rate on day 42 increased for cows with $\mathrm{BCS} \geq 2.75$ and cows ovulating after the final $\mathrm{GnRH}$ injection of the Ovsynch protocol. Further, the pregnancy rate was higher for primiparous compared to multiparous cows using the Ovsynch protocol. Similarly, Jeong et al. (2014) observed increased pregnancy rates in cows with $\mathrm{BCS} \geq 3.00$ compared to those having a BCS $\leq 2.75$. More recent data show a greater impact of changes in BCS during the postpartum period rather than the body condition at the beginning of the programme. This effect could be partially explained by the reduction in embryo quality by day 7 after TAI in cows that lost more body weight during the first three weeks of the postpartum period (Carvalho et al. 2014). A significant change in the body condition affected the onset of the first ovulation after parturition, the percentage of cyclic cows at 50 days in milk (DIM) and of pregnant cows. The pregnancy rate at day 32 was 18,33 and $47 \%$ for cows that lost, maintained or gained weight (Barletta et al. 2017). The body condition changes are directly related to the nutrition in the postpartum period, which influences the postpartum ovarian cyclicity and the conception rates after Ovsynch/TAI. Delayed recovery of ovarian cyclicity in cows causes decreased conception rates (Yamada et al. 2003).

\section{Age, lactation number, stage of lactation and production level}

The conception rate of primiparous cows after Ovsynch was significantly lower than that of cows without the Ovsynch protocol (37.84\% vs $71.05 \%)$; whereas no difference was found for the other lactation groups (Klindworth et al. 2001). On the other hand, primiparous cows were more likely pregnant compared to multiparous cows when Ovsynch was used (Yániz et al. 2004; Jeong et al. 2014). The conception rates for primiparous and multiparous cows were $37.9 \%$ vs $31.6 \%$, respectively. Likewise, pregnancy rates at 200 DIM were higher in primiparous cows $(81.8 \%$ vs $75.4 \%)$ when Ovsynch was applied (Tenhagen et al. 2004). At TAI following Ovsynch seems to have no beneficial effects in heifers due to an inconsistent follicle wave pattern, and also in anoestrous cows, given their lack of the endogenic prostaglandin response (Yániz et al. 2004). The overall synchronization rate (proportion of cows with an ovulation within $40 \mathrm{~h}$ after $\mathrm{GnRH}$ ) was $86.8 \%$ in primiparous and $88.2 \%$ in multiparous cows, respectively. Ovulation occurred earlier in primiparous compared to multiparous cows and ovulatory follicles were smaller. Conception rates were numerically higher in primiparous cows but the difference was not significant. Cows that displayed signs of oestrus on the day before the second $\mathrm{GnRH}$ injection and received an additional TAI on this day were more likely to conceive than cows that only received TAI 16 to $20 \mathrm{~h}$ after the second GnRH injection. To sum up, 
ovulation occurs earlier in primiparous compared to multiparous cows after the Ovsynch. However, the probability of conception could not be established (Tenhagen et al. 2003a). The differences in pregnancy rates after Ovsynch depend also on the rate of embryonic losses. Those were increasing from $11.5 \%$ to $22.1 \%$ and $21.8 \%$ in primiparous and in cows of second to third or more lactations, respectively. On the basis of risk analysis of embryonic loss, a significant association for parity and season of calving was established. Multiparous cows had a higher risk of embryonic loss than primiparous cows (hazard ratio $=1.32$ and 1.89 , respectively) (El-Tarabany et al. 2016).

The conception rate for high $(>28.5 \mathrm{~kg})$ and low $(\leq 28.5 \mathrm{~kg})$ milk producing cows after the Ovsynch was 6 and $16 \%$, respectively. Primiparous cows and those with a high milk production on the day of cyst diagnosis were more likely to become pregnant following Ovsynch treatment than multiparous cows and cows with a low milk production (Crane et al. 2006). Low-producing cows subjected to the Ovsynch protocol three weeks earlier (day 73-81 after parturition) than the rest of the herd had lower conception in comparison to cows inseminated later (14.4\% vs $34.5 \%)$. Similarly, in high-producing cows inseminated three weeks later the conception rate was $41.4 \%$ vs $28.2 \%$. Therefore, milk production level had no significant impact on the conception rates after TAI in cows synchronized at the same stage of lactation. Fewer cows with a high production level at 200 DIM were pregnant than cows with an average or low production. In conclusion, the stage of lactation, but not the milk production level, had a major influence on the conception rates after TAI. Therefore, in such cases profitability should be evaluated (Tenhagen et al. 2003b).

\section{Metabolic diseases and postpartum complications}

Understanding the causes and consequences of metabolic changes during the transition period is important for the health of cows and the efficiency of the Ovsynch protocol. In this case, a negative energy balance at the transition period is particularly important as it decides of health, reproduction and metabolic inflammation in the postpartum period of dairy animals (Wankhade et al. 2017). However, endometritis diagnosed and treated 4 weeks post partum did not influence the conception rates after TAI (Tenhagen et al. 2003b). On the other hand, the occurrence of lameness and mastitis decreased the chance of conception. Healthy cows had higher conception rates $(65.2 \%)$ than sick cows (35.9\%). Mean days open were fewer in healthy than in sick cows (85 vs 110 days). Cows becoming diseased were older (4.0 vs 2.8 of lactations) and had a decreased BCS (2.72 vs 2.91). However, no differences were found between healthy and non-healthy cows from the Ovsynch group with regard to the 100-day milk yield and the absolute milk fat and protein content (Klindworth et al. 2004). The prevalence of subclinical endometritis in postpartum dairy cows at 21 to 62 DIM in Argentina was $17 \%$, which was diagnosed by the proportion of leukocytes in the cytological material from the uterus cervix (cytobrush). Subclinical endometritis increased the interval from calving to conception and reduced the odds for pregnancy when comparing to the control group (Madoz et al. 2013). A negative energy balance can cause changes in the biochemical composition of the oestrous mucus, in extreme cases even of postpartum anoestrus (Jaśkowski et al. 2017). It was found that the greater the urea content in the cervical mucus, the greater the proportion of cows inseminated at an inappropriate time (Beran et al. 2013). Different studies show that 30\% of cows have not presented any signs of oestrus postpartum (Shephard 2005; Jaśkowski et al. 2018b). Mainly, it concerned cows that were young, recently calved and in low body condition. In that case, the Ovsynch can be used as a reasonable treatment option. The Ovsynch/TAI application resulted in a conception rate of 35.7\% and 33.2\%, 21-day pregnancy rates of $54.5 \%$ and $48.4 \%$, and 42 -day pregnancy rates of $69.7 \%$ and $62.6 \%$, for cycling cows and cows with no visible oestrous, respectively. Odds of pregnancy increased 
significantly for cows calved more than 40 days by the planned start of mating, in greater body condition and cycling (Shephard et al. 2005). Although $20 \%$ of lactating cows did not show any ovarian activity at about day 60 post partum, nearly all ovulated after the Ovsynch protocol (Gümen et al. 2003).

\section{Functional status of the ovaries and the phase of the oestrous cycle}

Both the presence and size of a follicular structure affected the odds of pregnancy, although cows with larger follicular structures were less likely to have a concurrent corpus luteum (CL) (Ingenhoff et al. 2017). The size of the CL and the presence of luteal cysts at the beginning of the Ovsynch programme increased the odds of conception (Klindworth et al. 2004). It was also established that the knowledge of the ovarian status determined by the ultrasound and the use of a specific synchronization programme and TAI allows to increase two times the odds of conception when compared to Ovsynch alone. The response to a specific oestrus synchronization protocol applied according to the ovarian status is more effective than the response to the Ovsynch protocol applied without taking into account the ovarian status of the animals (López-Gatius et al. 2004). Although overall synchronization rate with the Ovsynch programme was more than $85 \%$, there were differences in the response according to the day of protocol initiation during the oestrus cycle. Cows in which Ovsynch was initiated near mid-cycle had smaller follicles and higher pregnancy rates (Vasconcelos et al. 1999).

The percentage of cows ovulating after the first GnRH injection was $64 \%$ and varied by the stage of the oestrous cycle (Vasconcelos et al. 1999). Treatment with prostaglandin was effective in $93 \%$ of cows having low progesterone level at the second GnRH injection. The overall percentage of cows that ovulated after the second GnRH (synchronization rate) was $87 \%$ and varied in response to the first GnRH application $(92 \%$ if ovulation occurred after the first GnRH vs $79 \%$ without ovulation). There were $6 \%$ of cows that ovulated before the second injection of GnRH and 7\% with no detectable ovulation by $48 \mathrm{~h}$ after the final GnRH injection. The pregnancy rate after Ovsynch initiated on known days of the oestrous cycle was evaluated 28 and 98 days after insemination and it was lower for cows with larger follicles than those with smaller follicles (32 vs 42\%) (Vasconcelos et al. 1999). Initiating the Ovsynch protocol six days after oestrus during the first 40 days post partum resulted in a higher pregnancy rate compared to when the Ovsynch protocol was initiated at random stages of the oestrous cycle. Also, more cows in which the Ovsynch was initiated on day 6 responded to the second GnRH injection $(82.5 \%$ compared to $75.8 \%)$ (Dirandeh 2014). Success of Ovsynch was dependent on the progesterone concentrations on the day when the GnRH injection was given. Ovulation outcomes were greater at lesser progesterone concentrations after both $\mathrm{GnRH}$ injections. The incident of pregnancy was more likely when progesterone exceeded $3 \mathrm{ng} / \mathrm{ml}$ before the first $\mathrm{GnRH}$ injection and on the day of the prostaglandin $\left(\mathrm{PGF}_{2 \alpha}\right)$ application. Ovulation and pregnancy after the final GnRH injection were positively related to lesser concentrations of progesterone at $48 \mathrm{~h}$ after $\mathrm{PGF}_{2 a}$. However, the highest pregnancy rates were noted when progesterone concentration was $<0.5 \mathrm{ng} / \mathrm{ml}$. Cows with an additional $\mathrm{CL}$ after $\mathrm{GnRH}$ had the greatest pregnancy outcome when compared to anovulatory cows and those near oestrus without a CL at $\mathrm{GnRH}$ treatment. Except body condition, the size of the ovulatory follicle and the lactation number, the concentration of progesterone at a time when prostaglandin is administered, is highly predictive of ovulation and pregnancy risk (Stevenson 2016). In cows with high progesterone concentration at the onset of Ovsynch a significant improvement of pregnancy rate was noted over values obtained following progesterone releasing intra-vaginal device (PRID) or PRID/GnRH treatment. Cows with low progesterone concentration treated with PRID or PRID/GnRH showed increased ovulation and pregnancy rates compared to the 
Ovsynch treatment. These findings suggest the importance of establishing the ovarian status in early postpartum dairy cows before starting the Ovsynch protocol, in terms of luteal activity assessed by blood progesterone (Murugavel et al. 2003).

\section{Temperature, season, and year}

Many researchers highlight the negative impact of high temperature and humidity on the oestrus expression and conception rates of cows. A decreased pregnancy rate was noted when Ovsynch was conducted during summer compared to those conducted in autumn (De Renis et al. 2008; Jeong et al. 2014). The impact of season on cows' fertility submitted to the Ovsynch protocol or the modified method (the final GnRH injection was replaced by human chorion gonadotropin) was the overriding factor (De Renis et al. 2006). The use of the Ovsynch protocol between 50 and 70 DIM during summer and TAI independent of oestrus expression did not result in higher conception rates compared to cows inseminated after oestrus detection. An explanation for that is the higher rate of pregnancy losses between days 27-30 and 40-50 after TAI, noted in cows with no oestrus expression during insemination (Cartamil et al. 2001). Further, a different study showed that the pregnancy losses were higher in summer than in winter and greater for multiparous than for primiparous cows (Alnimer et al. 2009). Due to the presence of significant interactions of treatment, parity and season, ovulation synchronization protocols should be tailored according to individual conditions (Alnimer et al. 2009). The conception rate after the Ovsynch/TAI bred in July to August was low in cows that were on day 40 to 60 post partum, those in their $5^{\text {th }}$ or more lactations and those recovering ovarian cyclicity later than on day 56 post partum (Yamada 2005). The conception rates after the Ovsynch protocol tend to differ depending on the year. For example, in 1997 the First Service Conception rate (FSC) for Ovsynch showed no difference when compared to the control group (48.94\% vs $55.45 \%$; $P$ $>0.05)$, whereas in the next year the FSC for Ovsynch was significantly lower than in the control group (29.27\% vs $52.78 \%$ ) (Klinworth et al. 2001).

\section{Ovsynch modifications}

Strategies that optimize ovulation after the GnRH injection as well as those that induce ovulation after the final GnRH injection can improve effectiveness of the Ovsynch protocol. These strategies have already been a subject of many studies (Galvão and Santos 2010; Nowicki et al. 2017; Jaśkowski et al. 2018a). The easiest way to increase the effectiveness of the Ovsynch protocol is Presynch which includes two prostaglandin injections (Jaśkowski et al. 2018a). Such treatment results in Ovsynch fertility improvement (Thatcher et al. 2002; Peters and Pursley 2003; Marquezini et al. 2011; Carvalho et al. 2015a;b). Two prostaglandin injections with a 14 days interval 28 days before the onset of Ovsynch resulted in an increased conception rates from $37.3 \%$ (Ovsynch) to $49.6 \%$ (Mirmahmoudi and Prakash 2012). The Ovsynch effectiveness can also be increased by a preliminary PGF injection and a GnRH injection two days later (Carvalho et al. 2015 b). It was determined that pre-synchronization with GnRH injection 6 or 7 days (G6G or G7G) before the initial GnRH injection at the beginning of the Ovsynch protocol tended to increase the progesterone concentration at the onset of the Ovsynch protocol, and when prostaglandin was applied, there was an increase in oestrus synchronization after the final GnRH injection. This resulted in higher conception rates than in the classical Ovsynch protocol (Carvalho et al. 2015a;b). An increase in the proportion of cows with visible signs of oestrus and with completed luteolysis, as well as a higher rate of conceptions can be obtained by choosing a different way of prostaglandin application and different doses (Meira et al. 2006; Liu et al. 2017). The pregnancy rate was 57.2\% after ischiorectal fossa 
(IRF) injection of conventional dinoprost dose whereas the intramuscular injection resulted in $52.6 \%$ pregnancies (Holland 2015). An additional prostaglandin injection given a few hours after the first one resulted in higher percentage of cows with completed luteolysis and ovulating after the GnRH injection (Valldecabres-Torres et al. 2013; Liu et al. 2018). The efficacy of the Ovsynch program in improving conception and pregnancy rates was compared with untreated controls and other programs. The evaluated programs included Ovsynch, natural breeding, single, double or triple prostaglandin injections, Select Synch, Heat Synch, and modified Ovsynch. Pregnancy rates for Ovsynch programmes did not differ significantly from those with natural breeding programs [predicted Bayesian relative risk $(\mathrm{RR})=1.04,95 \%$ Bayesian credible interval $=0.36$ to 3.23]. Results of Ovsynch vs $\mathrm{PGF}_{2 \alpha}(2 \times \mathrm{PGF})$ programmes showed that the risk of conception and pregnancy rates predicted did not differ between the Ovsynch group and cows in the $\mathrm{PGF}_{2 \alpha}$ group. The conception and pregnancy rates obtained with prostaglandin, Select Synch and modified Ovsynch (including Presynch and CoSynch) programmes were comparable with the Ovsynch programme. Modifications to the Ovsynch program such as pre-synchronization and timed artificial insemination at the time of the second GnRH injection (CoSynch) may be an alternative for reproductive management of dairy herds where detection of oestrus is less than optimal (Rabiee et al. 2005). An improvement of the fertility ratio was obtained by time management of the first insemination (Stangaferro et al. 2018b). Cows were treated with one of three protocols: a) TAI after the Double-Ovsynch protocol (GnRH, 7 days later $\mathrm{PGF}_{2 a}, 3$ days later $\mathrm{GnRH}, 7$ days later $\mathrm{GnRH}, 7 \mathrm{~d}$ later $\mathrm{PGF}_{2 a}, 56 \mathrm{~h}$ later GnRH and 16 to $18 \mathrm{~h}$ later TAI) at 60 DIM (DO60), b) TAI after Double-Ovsynch at 88 \pm 3 DIM (DO88), c) combination of AI at detected estrus (starting at $50 \pm 3$ DIM) and TAI with the Presynch-Ovsynch protocol $\left(\mathrm{PGF}_{2 \alpha}, 14 \mathrm{~d}_{\text {later }} \mathrm{PGF}_{2 \alpha}, 12 \mathrm{~d}\right.$ later GnRH, $7 \mathrm{~d}$ later $\mathrm{PGF}_{2 \alpha}, 56 \mathrm{~h}$ later GnRH, and 16 to $18 \mathrm{~h}$ later TAI PSOv $=450$ ). Cows treated with TAI/Ovsynch in the DO88 group had improved uterine health, greater BCS, and reduced incidence of anovulation than cows in DO60. However, overall pregnancy on day 39 after AI did not differ. Nevertheless, despite the higher first conception rate, extended time to pregnancy after calving and higher possibility to leave the herd was noted (Stangaferro et al. 2018b). The reproductive strategies based on artificial insemination at detected oestrus or after the Presynch/Ovsynch or Double-Ovsynch protocol resulted in reduced time to pregnancy after calving when compared with a TAI of 88 days (Stangaferro et al. 2018a). Another study confirms this as the overall conception rate and first service conception rate were higher in cows that received heat artificial insemination (HAI) compared to FTAI (33.8 vs $21.3 \%$, and 35.3 vs $21.0 \%$ ) (Kasimanickam et al. 2005).

The efficacy of the Ovsych protocol is determined by various individual and environmental components such as body condition, age, ovarian status, co-existing health problems, season, outdoor temperature, year, time of the Ovsynch onset and to a minor extent production level. The efficiency of the Ovsynch program can be increased by introducing modifications to it and by making adjustments regarding its starting date after calving. Interactions of the Ovsynch and its modifications with the season and age of cows (primiparous, multiparous) and their relationship with fertility seem to indicate the need for a precise individual selection of the synchronization protocol taking into account the influence of those factors.

\section{References}

Alnimer MAA, Tabbaa MJ, Ababneh MM, Lubbadeh WF 2009: Applying variations of the Ovsynch protocol at the middle of the estrus cycle on reproductive performance of lactating dairy cows during summer and winter. Theriogenology 72: 731-740

Barletta RV, Maturana Filho M, Carvalho PD, Del Valle TA, Netto AS, Rennó FP, Mingoti RD, Gandra JR, Mourão GB, Fricke PM, Sartori R, Madureira EH, Wiltbank MC 2017: Association of changes among body condition 
score during the transition period with NEFA and BHBA concentrations, milk production, fertility, and health of Holstein cows. Theriogenology 104: 30-36

Beran J, Stádník L, Ducháček J, Okrouhlá M, Doležalová M, Kadlecová V, Ptáček M 2013: Relationships among the cervical mucus urea and acetone, accuracy of insemination timing, and sperm survival in Holstein cows. Anim Reprod Sci 142: 28-34

Caraviello DZ, Weigel KA, Fricke PM, Wiltbank MC, Florent MJ, Cook NB, Nordlund KV, Zwaland NR, Rawson CL 2006: Survey of management practices on reproductive performance of dairy cattle on large US commercial farms. J Dairy Sci 89: 4723-4735

Cartamill JA, El-Zarkouny SZ, Hensley BA, Rozell TG, Smith JF, Stevenson JS 2001: An alternative AI breeding protocol for dairy cows exposed to elevated ambient temperatures before or after calving or both. J Dairy Sci 84: 799-806

Carvalho PD, Souza AH, Amundson MC, Hackbart KS, Fuenzalida MJ, Herlihy MM, Ayres H, Dresch AR, Vieira LM, Guenther JN, Grummer RR, Fricke PM, Shaver RD, Wiltbank MC 2014: Relationships between fertility and postpartum changes in body condition and body weight in lactating dairy cows. J Dairy Sci 97: 3666-3683

Carvalho PD, Fuenzalida MJ, Ricci AH, Souza RV, Barletta MC, Wiltbank MC, Fricke PM 2015a: Modifications to Ovsynch improve fertility during resynchronization: Evaluation of presynchronization with GnRH 6 days before Ovsynch and addition of a second prostaglandin F2 $\alpha$ treatment. J Dairy Sci 98: 8741-8752

Carvalho PD, Wiltbank MC, Fricke PM 2015b: Manipulation of progesterone to increase ovulatory response to the first GnRH treatment of an Ovsynch protocol in lactating dairy cows receiving first timed artificial insemination. J Dairy Sci 98: 8800-8813

Crane MB, Melendez P, Bartolome J, de Vries A, Risco C, Archbald LF 2006: Association between milk production and treatment response of ovarian cysts in lactating dairy cows using the Ovsynch protocol. Theriogenology 66: 1243-1248

De Renis F, López-Gatius F, Capelli T, Molina E, Techakumphu M, Scaramuzzi RJ 2008: Effect of season on luteal activity during the post partum period of dairy cows in temperate areas. Animal 2: 554-559

Denis-Robichaud J, Cerri RLA, Jones-Bitton A, LeBlanc SJ 2016: Survey of reproduction management on Canadian dairy farms. J Dairy Sci 99: 9339-9351

Dirandeh E 2014: Starting Ovsynch protocol on day 6 of first postpartum estrous cycle increased fertility in dairy cows by affecting ovarian response during heat stress. Anim Reprod Sci 149: 135-140

El-Tarabany MS, El-Tarabany AA, Roushdy EM 2016: Impact of parity on the efficiency of ovulation synchronization protocols in Holstein cows. Theriogenology 86: 2230-2237

Galvão KN, Santos JE 2010: Factors affecting synchronization and conception rate after the Ovsynch protocol in lactating Holstein cows. Reprod Domest Anim 45: 439-446

Gümen A, Guenther JN, Wiltbank MC 2003: Follicular size and response to Ovsynch versus detection of estrus in anovular and ovular lactating dairy cows. J Dairy Sci 86: 3184-3194

Holland SC 2015: Comparison of luteolysis and timed artificial insemination pregnancy rates after administration of PGF2 $\alpha$ in the muscle or the ischiorectal fossa in cattle PhD thesis, May 26, Blacksburg, VA, pp 36-67

Ingenhoff L, Hall E, Ranjbar Ni S, House JK 2017: Effects of ovarian structures identified at Ovsynch ${ }^{\mathrm{TM}}$ enrolment, disease history and lactation variables on odds of pregnancy to a fixed-time artificial insemination after Ovsynch ${ }^{\mathrm{TM}}$. Aust Vet J 95: 110-117

Jaskowski BM, Kulus J, Kmiecik J, Nowak T, Boryczko Z 2017: Anoestrus in cows - the effectiveness of different therapy models. Biotechnology used in the reproduction of farm animals and horses, pp 101-108

Jaskowski JM, Olechnowicz J, Nowak W 2006: Some causes of declining fertility in dairy cows. Med Weter 62: $385-389$

Jaskowski JM, Herudzinska M, Kulus J, Brüssow KP, Gehrke M 2018a: OvSynch program, its modifications and alternative hormonal programs in cow reproduction. Med Weter 74: 626-633

Jaskowski JM, Kmiecik J, Kierbic A, Herudzinska M, Wozna-Wysocka M 2018b: Automatic systems for heat detection in cows as a tool for improving herd management. Med Weter 74: 434-440

Jeong JK, Kong HG, Jung TH, Hur TY, Kim IH 2014: Risk factors for the probability of pregnancy following synchronization protocols in dairy cows. J Vet Clin 31: 382-388

Kasimanickam R, Cornwell JM, Nebel RL 2005: Fertility following fixed-time AI or insemination at observed estrus in Ovsynch and Heatsynch programs in lactating dairy cows. Theriogenology 63: 2550-2559

Klindworth HP, Hoedemaker M, Burfeindt D, Heilkenbrinker T 2001: Synchronization of ovulation (OVSYNCH) in high-producing dairy cattle herds. I. Fertility parameters, body condition score and plama progesterone contration. Dtsch Tierarztl Wochenschr 108: 11-19

Klindworth HP, Hoedemaker M, Burfeindt D, Heilkenbrinker T 2004: Synchronization of ovulation (OVSYNCH) in high producing dairy cattle herds. Part II: Milk yield, diseases and cost-benefit-analysis. Dtsch Tierarztl Wochenschr 111: 142-147

Liu TC, Chiang CF, Ho CT, Chan JP 2018: Effect of GnRH on ovulatory response after luteolysis induced by two low doses of PGF2 $\alpha$ in lactating dairy cows. Theriogenology 105: 45-50

Liu TC, Ho CY, Chan JP 2017: Effect of two low doses of prostaglandin F2 $\alpha$ on luteolysis in dairy cows. Acta Vet Hung 65: 105-114

Lòpez-Gatius F, Murugavel K, Santolaria P, López-Béjar M, Yániz JL 2004: Pregnancy Rate after Timed Artificial 
Insemination in Early Post-partum Dairy Cows after Ovsynch or Specific Synchronization Protocols. J Vet Med 51: $33-38$

Macmillan KL 2010: Recent advances in the synchronization of estrus and ovulation in dairy cows. J Reprod Dev 56: $42-47$

Madoz LV, Giuliodori MJ, Jaureguiberry M, Plöntzke J, Drillich M, de la Sota RL 2013: The relationship between endometrial cytology during estrous cycle and cutoff points for the diagnosis of subclinical endometritis in grazing dairy cows. J Dairy Sci 96: 4333-4339

Marquezini GH, Dahlen CR, Bird SL, Lamb GC 2011: Administration of human chorionic gonadotropin to suckled beef cows before ovulation synchronization and fixed-time insemination: replacement of gonadotropin-releasing hormone with human chorionic gonadotropin. J Anim Sci 89: 3030-3039

Meira C, Pessoa VM, Ferreira JC, Araujo GH, Gioso MM, Bicudo SD, Oba E, Orlandi C 2006: Alternative low doses and routes of administering a prostaglandin F2alpha analogue to induce luteolysis in Nelore cows. J Vet Sci 7: 387-390

Mirmahmoudi R, Prakash BS 2012: The endocrine changes, the timing of ovulation and the efficacy of the Doublesynch protocol in the Murrah buffalo (Bubalus bubalis). Gen Comp Endocrinol 177: 153-159

Moreira F, Risco C, Pires MF, Ambrose JD, Drost M, DeLorenzo M, Thatcher WW 2000: Effect of body condition on reproductive efficiency of lactating dairy cows receiving a timed insemination. Theriogenology 53: 1305-1319

Murugavel K, Yániz JL, Santolaria P, López-Béjar M, López-Gatius F 2003: Luteal activity at the onset of a timed insemination protocol affects reproductive outcome in early postpartum dairy cows. Theriogenology 60: 583-593

Nowicki A, Barański W, Baryczka A, Janowski T 2017: OvSynch protocol and its modifications in the reproduction management of dairy cattle herds. J Vet Res 61: 329-336

Peters MW, Pursley JR 2003: Timing of final GnRH of the Ovsynch protocol affects ovulatory follicle size, subsequent luteal function, and fertility in dairy cows. Theriogenology 60: 1197-1204

Pursley JR, Mee MO, Wiltbank MC 1995: Synchronization of ovulation in dairy cows using PGF 2 alpha and GnRH. Theriogenology 44: 915-923

Rabiee AR, Lean IJ, Stevenson MA 2005: Efficacy of Ovsynch program on reproductive performance in dairy cattle: a meta-analysis. J Dairy Sci 88: 2754-70

Shephard RW 2005: A comparison of performance of the Ovsynch treatment program between cycling and noncycling cows within seasonally-calving dairy herds. Aust Vet J 83: 751-757

Stangaferro ML, Wijma R, Masello M, Giordano JO 2018a: Reproductive performance and herd exit dynamics of lactating dairy cows managed for first service with the Presynch-Ovsynch or Double-Ovsynch protocol and different duration of the voluntary waiting period. J Dairy Sci 101: 1673-1686

Stangaferro ML, Wijma R, Masello M, Thomas MJ, Giordano JO 2018b: Extending the duration of the voluntary waiting period from 60 to 88 days in cows that received timed artificial insemination after the Double-Ovsynch protocol affected the reproductive performance, herd exit dynamics, and lactation performance of dairy cows. J Dairy Sci 101: 717-735

Stevenson JS 2016: Physiological predictors of ovulation and pregnancy risk in a fixed-time artificial insemination program. J Dairy Sci 99: 10077-10092

Tenhagen BA, Surholt R, Wittke M, Vogel C, Drillich M, Heuwieser W 2004: Use of Ovsynch in dairy herds-differences between primiparous and multiparous cows. Anim Reprod Sci 81: 1-11

Tenhagen BA, Vogel C, Drillich M, Thiele G, Heuwieser W 2003a: Influence of stage of lactation and milk production on conception rates after timed artificial insemination following Ovsynch. Theriogenology 60: 1527-1537

Tenhagen BA, Wittke M, Drillich M, Heuwieser W 2003b: Timing of ovulation and conception rate in primiparous and multiparous cows after synchronization of ovulation with GnRH and PGF2alpha. Reprod Domest Anim 38: $451-454$

Thatcher WW, Moreira F, Pancarci SM, Bartolome JA, Santos JE 2002: Strategies to optimize reproductive efficiency by regulation of ovarian function. Domest Anim Endocrinol 23: 243-254

Valldecabres-Torres X, Larrosa-Morales P, Cuervo-Arango J 2013: The effect of dose and type of cloprostenol on the luteolytic response of dairy cattle during the Ovsynch protocol under different oestrous cycle and physiological characteristics. Reprod Domest Anim 48: 874-880

Vasconcelos JL, Silcox RW, Rosa GJ, Pursley JR, Wiltbank MC 1999: Synchronization rate, size of the ovulatory follicle, and pregnancy rate after synchronization of ovulation beginning on different days of the estrous cycle in lactating dairy cows. Theriogenology 52: 1067-78

Yamada K 2005: Development of ovulation synchronization and fixed time artificial insemination in dairy cows. J Reprod \& Fertil 51: 177-186

Yamada K, Nakao T, Isobe N 2003: Effects of body condition score in cows peripartum on the onset of postpartum ovarian cyclicity and conception rates after ovulation synchronization/fixed-time artificial insemination. J Reprod Dev 49: 381-388

Yániz JL, Murugavel K, López-Gatius F 2004: Recent developments in oestrous synchronization of postpartum dairy cows with and without ovarian disorders. Reprod Domest Anim 39: 86-93

Wankhade PR, Manimaran A, Kumaresan A, Jeyakumar S, Ramesha KP, Sejian V, Rajendran D, Varghese MR 2017: Metabolic and immunological changes in transition dairy cows: A review. Vet World, 10: 1367-1377 